\title{
Nevirapine Hepatotoxicity: Case Report and Discussion
}

\author{
Matt Baichi \\ Thomas Jefferson University
}

Follow this and additional works at: https://jdc.jefferson.edu/tmf

Part of the Gastroenterology Commons, Medical Pharmacology Commons, and the Medical Toxicology Commons

\section{Let us know how access to this document benefits you}

\section{Recommended Citation}

Baichi, Matt (2003) "Nevirapine Hepatotoxicity: Case Report and Discussion," The Medicine Forum: Vol. 4 , Article 6.

DOI: https://doi.org/10.29046/TMF.004.1.007

Available at: https://jdc.jefferson.edu/tmf/vol4/iss $1 / 6$

This Article is brought to you for free and open access by the Jefferson Digital Commons. The Jefferson Digital Commons is a service of Thomas Jefferson University's Center for Teaching and Learning (CTL). The Commons is a showcase for Jefferson books and journals, peer-reviewed scholarly publications, unique historical collections from the University archives, and teaching tools. The Jefferson Digital Commons allows researchers and interested readers anywhere in the world to learn about and keep up to date with Jefferson scholarship. This article has been accepted for inclusion in The Medicine Forum by an authorized administrator of the Jefferson Digital Commons. For more information, please contact: JeffersonDigitalCommons@jefferson.edu. 


\section{Nevirapine Hepatotoxicity: Case Report And Discussion}

Matt Baichi, MD, Resident, Internal Medicine 2000-2003

\section{Introduction}

Nevirapine (viramune) is a nonnucleoside reverse transcriptase inhibitor commonly used in combination with other antiretroviral medicines in the treatment of HIV/AIDS. The safety profile of nevirapine, as determined by review of prospective clinical trials ${ }^{1}$, reports rash with an incidence of $16 \%$ as the most common side effect. Clinical hepatitis is reported to occur with an incidence of $1 \%$. A review of the literature shows many case reports of nevirapine-induced hepatotoxicity in patients receiving both treatment and prophylaxis for HIV ${ }^{2-6}$. The purpose of this case report is to stress the importance of early recognition and withdrawal of the offending drug.

\section{Case Report}

A 48 year old African American male with a past medical history of AIDS, chronic hepatitis C, and hypertension presented as a transfer from an outside hospital with a rash and elevated aminotransferases. Since diagnosis of AIDS in 1995, the patient had been on lamivudine, zidovudine, and indinavir with an undetectable viral load and CD4 count of 253 cells/ul. Due to recurrent kidney stones, the patient was switched from indinavir to nevirapine about three weeks prior to admission. Nevirapine was started at low dose for two weeks before increasing to full dose therapy. After three days of full dose therapy, he noted fever, chills, and diffuse body aches.

The patient reported to the emergency room and was admitted with a fever of $101 \mathrm{~F}$. At the time of admission, he denied headache, sore throat, stiff neck, shortness of breath, cough, abdominal pain, arthralgia, or rash. Physical exam revealed sinus tenderness, anicteric sclera, no pharyngeal erythema or exudate, supple neck, clear lungs, regular heart rate and rhythm, soft non-tender abdomen with no hepatomegaly, non-focal neurologic exam, and no rash. Complete blood count and chemistries were within normal limits. Liver chemistries were not ordered at initial presentation. Chest x-ray showed new mild elevation of right hemi-diaphragm with no consolidation. Sinus x-rays was normal.

The patient was started on ampicillin/sulbactam after which he developed a diffuse erythematous rash that resolved with discontinuation of antibiotics and administration of intravenous methylprednisolone and diphenhydramine. The fever did not recur with discontinuation of antibiotics. He was discharged on his admission antiretroviral medications. A few days after discharge, the fever and rash reappeared along with scleral icteris and light colored loose stool. He was readmitted and then transferred to our hospital.

On admission, he denied any alcohol since 1995, denied any recent travel or ingestion of contaminated food, denied taking any over the counter drugs, vitamins, or herbal remedies. He also denied any family history of liver disease. He admitted to having been vaccinated against hepatitis $\mathrm{A}$ and $\mathrm{B}$. $\mathrm{He}$ was taking lamivudine/zidovudine, clonidine, atenolol, fosinopril, and furosemide. He chose to stop taking the nevirapine, believing that it might have been responsible for his illness. Physical exam was notable for scleral icterus, hepatomegaly, and diffuse erythematous maculopapular rash. Total bilirubin was $6.6 \mathrm{mg} / \mathrm{dl}$, direct bilirubin 4.1 $\mathrm{mg} / \mathrm{dl}$, ALT $173 \mathrm{U} / \mathrm{L}$, and INR 1.2. Abdominal ultrasound showed only hepatomegaly.

The patient was believed to have nevirapine-induced hepatitis. All medicines were held. ALT peaked at $720 \mathrm{U} / \mathrm{L}$ (hospital day seven). Total bilirubin peaked at $30.9 \mathrm{mg} / \mathrm{dl}$ (hospital day nine). INR peaked at 2.0 (hospital day nine). The rash improved steadily, hepatomegaly resolved, and the patient remained afebrile. Blood and urine cultures were negative. Hepatitis A virus IgM, Hepatitis B virus core IgM, Hepatitis B virus surface antigen, and acetaminophen levels were all negative. The patient was discharged on hospital day eleven. His liver function tests returned to baseline over the next five months.

\section{Discussion}

Hepatotoxicity is a potential complication of many common drugs. As new drugs enter clinical practice, case reports of drug-induced hepatotoxicity will follow. Such is the case with nevirapine. Since its introduction in 1996, several case reports have described severe toxic hepatitis. Drug induced hepatotoxicity is a relatively uncommon cause of acute hepatitis, but it is an important one. Risk factors for hepatotoxicity include 
age, gender, history of adverse drug reaction, polypharmacy, alcohol use, poor nutritional status, preexisting liver disease, and certain systemic diseases. Druginduced liver disease can mimic the clinicopathologic presentation of nearly all known liver diseases. Clinicopathologic features can therefore organize the classification of hepatotoxicity. Presentation can include acute or chronic hepatitis, acute or chronic cholestasis, mixed cholestatic hepatitis, fibrosis/cirrhosis, vascular injury, and tumors. Hepatotoxicity can be dose dependent or idiosyncratic. The clinical presentation of hepatotoxicity often includes early prodromal symptoms which if recognized, can allow early diagnosis and withdrawal of the toxic agent. These symptoms include fever, rash, mucositis, eosinophilia, lymphadenopathy, a mononucleosis-type syndrome, bone marrow suppression, vasculitis, renal failure, pneumonitis, and pancreatitis. Early diagnosis ultimately depends on high clinical suspicion. The physician must recognize these subtle symptoms and ask detailed questions concerning recent and remote drug history. Drug history must include temporal relationship to symptoms, doses, and use of non-prescription or herbal drugs. Diagnosis of drug-induced liver injury, however, can only be made after exclusion of infectious, autoimmune, vascular, and metabolic etiologies. There is no treatment other than removal of the offending agent and supportive care. This makes early detection the most significant task for the physician.

In this case, the patient presented with fever, malaise, myalgias, recent change in medication, and history of chronic hepatitis C. On initial presentation, no liver function studies were checked. In the previously reported cases of nevirapine hepatotoxicity ${ }^{2-6}$, symptoms occurred from two to six weeks after starting the drug. Nonspecific symptoms were uniformly present and included fever, rash, arthralgia, and malaise. Patterns of liver chemistries included pure hepatocellular, pure cholestasis, and mixed cholestatic hepatitis. In addition to recognition of early symptoms, recognition of risk factors can aid in early diagnosis by raising clinical suspicion. Two studies have looked at chronic hepatitis $\mathrm{B}$ or $\mathrm{C}$ as risk factors for hepatotoxicity during HAART in HIV patients. Both studies concluded that hepatotoxicity to HAART is more likely in patients co-infected with hepatitis B or $C^{9,10}$. This case serves as a reminder that hepatotoxicity is still overlooked during it's early phase.

\section{References}

1. Pollard RB, Robinson P, Dransfield K. Safety profile of nevirapine, a nonnucleoside reverse transcriptase inhibitor for the treatment of human immunodeficiency virus infection. Clin Ther 1998;20(6):1071-92.

2. Reiter GS. Hepatitis in an HIV-infected man. AIDS Clin Care 1997;9(10):78,81.

3. Leitze Z, Nadeem A, Choudhary A, et al. Nevirapineinduced hepatitis treated with corticosteroids. AIDS 1998;12(9):1115-17.

4. Cattelan AM, Erne E, Salatino A, et al. Severe hepatic failure related to nevirapine treatment. Clin Infect Dis 1999;29:455-6.

5. Anonymous. Serious adverse events attributed to nevirapine regimens for postexposure prophylaxis after HIV exposures-worldwide, 1997-2000. JAMA 2001;285(4):402-3.

6. Prakash M, Poreddy V, Tiyyagura L, et al. Jaundice and hepatocellular damage associated with nevirapine therapy. Am J Gastroenterol 2001; 96(5):1571-3.

7. Lee WM. Drug-induced hepatotoxicity. N Engl J Med 1995; 333(17):1118-26.

8. den Brinker M, Wit FWNM, Wertheim-van Dillen PME, et al. Hepatitis B and $\mathrm{C}$ virus co-infection and the risk for hepatotoxicity of highly active antiretroviral therapy in HIV-1 infection. AIDS 2000; 14: 2895-2902.

9. Sulkowski MS, Thomas DL, Chaisson RE, et al. Hepatotoxicity associated with antiretroviral therapy in adults infected with human immunodeficiency virus and the role of hepatitis C or B virus infection. JAMA 2000; 283(1): 74-80. 